\title{
Da igualdade de acesso à Justiça: Reflexões acerca da Defensoria Pública enquanto facilitadora de acesso dos Hipossuficientes
}

\author{
Josiéli Denise Brum dos Santos $^{1}$; Gisanne de Oliveira Marinho ${ }^{2}$; Athena de Albuquerque Farias ${ }^{3}$; \\ Larice de Sousa Rodrigues ${ }^{4}$
}

\begin{abstract}
Resumo: Busca-se estudar a desigualdade de acesso na justiça, tendo como objeto principal o exame da atuação da defensoria pública como meio de possibilitar esse acesso à todos e as dificuldades enfrentadas por essa no desenvolvimento de suas atividades. Para isto, será comentado brevemente acerca do histórico do acesso à Justiça, sobre os princípios basilares dessa garantia constitucional, e, em seguida, sobre o papel da Defensoria Pública como instituição mediadora e facilitadora desse acesso. Ao final, será comentado sobre as dificuldades inerente ao acesso à Justiça em decorrência da falta de valorização da Defensoria e suas problemáticas, a fim de demonstrar importância do investimento e desenvolvimento dessa instituição. Para alcançar o referido objetivo, utilizará de estudos bibliográficos, sobretudo, de obras que debatem o acesso à Justiça e as causas de mitigação desse, bem como sobre o papel da Defensoria Pública como ator colaborador desse do acesso à Justiça.
\end{abstract}

Palavras-Chave: Direito Penal. Justiça. Acesso à Justiça. Defensoria Pública. Princípios Constitucionais.

\section{Equal Access to Justice: Reflections on the Public Defender's Office as a facilitator of the access for the Hypo Sufficients}

\begin{abstract}
This article analyzes Access to justice as a form of inequality. Its main objective is the examination of the public defender's action as a way of enabling this access to all and the difficulties involved in its performance. From this, it will be briefly discussed about the history of access to justice, about the basic principles involved, and then about the role of the Public Defender as a mediating institution and facilitator of this access. At the end, it will be commented about the difficulties inherent in access to justice due to the lack of valorization of the Public Defender Offices and its problems, in order to demonstrate the importance of the investment and development of this institution. In order to achieve this goal, bibliographical studies will be used, mainly articles and works that discuss access to justice, as wells the role of the Public Defender Office as a collaborating actor in access to justice.
\end{abstract}

Key-words: Criminal Law. Justice. Access to justice. Public Defender Offices. Constitutional Principles

\footnotetext{
${ }^{1}$ Graduação em Direito pelo Centro Universitário SOCIESC - UNISOCIESC; Contato: josidenise1@ gmail.com;

${ }^{2}$ Graduação em Direiro pela Universidade Federal Fluminense. Mestranda em Justiça Administrativa pela Universidade Federal Fluminense. Contato: gisannemarinho@gmail.com;

${ }^{3}$ Graduação em Direito pela Faculdade dos Guararapes, Jaboatão dos Guararapes - PE; Especialização em Direito Processual do Trabalho pela Faculdades Integradas de Cruzeiro, Brasil. Contato: athena.farias@ gmail.com;

${ }^{4}$ Mestranda em Educação pela Unissulivan Inc. Contato: laricesousa2008@ hotmail.com.

271 Id on Line Rev. Mult. Psic. V.12, N. 40. 2018 - ISSN 1981-1179

Edição eletrônica em http://idonline.emnuvens.com.br/id
} 


\section{Introdução}

O princípio do acesso à justiça, trata-se de garantia constitucional que tem por escopo possibilitar a efetividade da tutela jurisdicional. A ideia de "justiça" carrega consigo a ideia de imparcialidade e igualdade de tratamento, perceptível, inclusive, simbologia que a representa, qual seja a balança, que representa isonomia e equidade.

No passado, a justiça era exercida pelos cidadãos em conflito, que exerciam a "justiça com as próprias mãos", o que nem sempre resultava na solução mais justa, momento em que o Estado viu a necessidade de interferir na resolução de possíveis litígios.

De início escolha da intervenção Estatal era facultativa, passando logo em seguida a ser obrigatória. Nessa, semelhante a um processo de arbitragem uma terceira pessoa imparcial era eleita pelas partes para julgar o caso.

No século XVII, após a efetiva repartição dos poderes, o Estado tomou para si o poder de dizer o direito e aplicar as leis, momento em que obteve o monopólio da jurisdição, passando a regular as relações jurídicas.

O Estado, como garantidor da paz social, avocou para si a solução monopolizada dos conflitos intersubjetivos pela transgressão à ordem jurídica, limitando o âmbito da autotutela. Em consequência, dotou um de seus Poderes, o Judiciário, da atribuição de solucionar os referidos conflitos mediante a aplicação do direito objetivo, abstratamente concebido, ao caso concreto (FUX, 2004, p.41)

Ao colocar-se como único e exclusivo detentor da tutela jurisdicional, o Estado foi compelido a dispor de garantias que possibilitassem o acesso integral e igualitário de todos à justiça, bem como a imparcialidade no julgamento, como se pode inferir do disposto no artigo $5^{\circ}$ da Constituição Federal de 1988:

\footnotetext{
"Art. $5^{\circ}$ - Todos são iguais perante a lei, sem distinção de qualquer natureza, garantindo-se aos brasileiros e aos estrangeiros residentes no País a inviolabilidade do direito à vida, à liberdade, à igualdade, à segurança e à propriedade, nos termos seguintes (...) XXXV - a lei não excluirá da apreciação do Poder Judiciário lesão ou ameaça a direito"
}

No entanto, mesmo sendo responsável pelo desenvolvimento de uma justiça igualitária e acessível a todos, diversas críticas versam no sentido de que tal garantia inexiste, como pode se verificar na seara penal, em que a proteção isonômica de todos os cidadãos é quase mitológica, visto que é perceptível que o direito penal aplica penalidades com intensidade e de 
maneira fragmentária, o que revela a distribuição do status de criminoso de modo desigual (BARATTA, 2002).

Assim, é notório que o sistema judicial, em especial de justiça criminal, revela a presença de um desequilíbrio quanto a distribuição de recursos. Diante disso, é necessário a análise do caso a fins de identificar as possíveis causas de desinteresse do Estado em desenvolver uma estrutura efetivamente equânime envolvendo os os agentes do sistema de justiça penal e o sistema punitivista vigente, para, ao final, encontrar possível soluções.

Esta situação, revela uma mitigação de acesso isonômico à justiça criminal, em que Defensoria Pública tem atuado no sentido de buscar a diminuição dessas mazelas, bem como o respeito aos limites constitucionais aos quais o direito penal encontra-se vinculado, sendo o objetivo desse trabalho analisar a atuação dessa instituição como agente facilitador do acesso à Justiça.

\section{Dos princípios constitucionais relacionados com o acesso à Justiça}

Entre os séculos XVI ao XIX, momento em que vigorou o jusnaturalismo, havia a ideia de que os direitos que eram um direito natural, ou seja, inerentes ao homem, não sendo estes decorrentes de normas. Logo em seguida, com o advento do Positivismo, o Direito passa a existir na forma única e exclusivamente de norma positivada. Sequencialmente, no século XX, com o fracasso do fascismo e do nazismo, surgiu o Pós-positivismo, que trouxe a valorização dos princípios, bem como a incorporação destes nos textos constitucionais, revelando uma aproximação do direito com a ética. Com isso, os princípios passaram ao status de norma ${ }^{4}$.

Como é sabido, hodiernamente, os princípios constitucionalmente dispostos são dotados de supremacia, sendo necessário sua observação para fins de possibilitar uma sociedade justa e igualitária. Nesse diapasão, dentre os princípios norteadores da Justiça, especificamente qual ao acesso à justiça, encontramos o princípio da isonomia, da legalidade e da dignidade da pessoa humana, que fazem parte do sistema judicial e devem ser observados pelo legislador quando da

\footnotetext{
${ }^{4}$ Sobre os princípios e as regras jurídicas, urge comentar que a maioria dos doutrinadores entendem que os princípios e regras possuem o mesmo status de norma jurídica, não havendo hierarquia entre eles, sendo os princípios normas que identificam valores a serem preservados que trazem um conteúdo axiológico ou uma decisão política (BARROSO, 2003).
} 
criação de uma norma, assim como pelos operadores no direito no exercício de suas funções da Igualdade ou Isonomia

O princípio da igualdade, está definido no artigo $5^{\circ}$, caput, da Carta Maior, que dispões o seguinte:

Todos são iguais perante a lei, sem distinção de qualquer natureza, garantindo-se aos brasileiros e aos estrangeiros residentes no País a inviolabilidade do direito à vida, à liberdade, à igualdade, à segurança e à propriedade.

Conforme comenta Bonavides (2003), o termo "igualdade" foi entendido primeiramente como igualdade natural, depois como igualdade civil e, por fim, teve os conceitos conciliados na declaração de direitos do Homem e do Cidadão à Constituição revolucionária da França, em 1789, quando definiu-se que "os homens nascem e são livres e iguais em direitos. As distinções sociais só podem fundamentar-se na utilidade comum"; momento em que o princípio igualitário se tornou fonte de inspiração e base das constituintes da modernidade estado moderno.

Assim, a igualdade passa a ter duas dimensões, sendo uma material e outra formal. A primeira está relacionada a uma igualdade substancial, efetivada por meio dos bens da vida. Por sua vez, a formal é a igualdade de todos perante a lei, que busca impedir que haja o privilégio de algumas pessoas perante a lei.

No entanto, apesar de consistir em um direito fundamental, a igualdade entre os cidadãos está longe de ser consolidada. de acordo com Luís Roberto Barroso (1994, p. 42):

O princípio da igualdade existe como postulado de caráter geral, com a missão de ser aplicado em todas as relações que envolverem o homem. É um direito fundamental que exige um comportamento voltado para que a lei seja tratada de modo igual para todos os cidadãos.

Contudo, o que se observa é que muitas vezes a igualdade não é efetivada no direito substancial $^{5}$, tampouco material $^{6}$, o que demonstra o desrespeito a esse princípio, apesar desse dever ser observado como critério básico quando da distribuição de uma prestação estatal.

\footnotetext{
5 Trata-se da igualdade no sentido formal, sendo esta a igualdade perante a lei, que consiste no tratamento equânime aos indivíduos, independentemente de cor, religião ou sexo.

${ }^{6}$ Segundo Pemthaler (1965 apud BONAVIDES, 2004, p. 379), "Pelo princípio da igualdade material entende-se, que o Estado se obriga mediante intervenções de retificação na ordem social a remover as mais profundas e perturbadoras injustiças sociais" 
No que concerne ao princípio da razoabilidade ou proporcionalidade, uma parte da doutrina faz distinção entre os mesmos, porém, neste trabalho esta diferenciação não será feita.

O princípio da proporcionalidade diz respeito a um sistema de valoração, ou seja, para garantir um direito, muitas vezes é necessário restringir outro, desde que se apresente mais importante, com conteúdo valorativo superior ao direito ao qual é comparado, ainda, a intervenção na esfera de direitos do particular deve ser proporcional à carga coativa, sem excessos. (SOUZA, 2003).

De acordo com Bonavides (2004), o princípio da proporcionalidade pode ser visto como uma nova garantia do Estado Democrático de Direito, tanto na proteção do cidadão em face do estado como no fortalecimento da função do juiz perante o legislador.

Para Bonavides (2004, p. 305):

\begin{abstract}
O princípio da razoabilidade permite ao judiciário invalidar atos legislativos ou administrativos quando: a) não haja adequação entre o fim perseguido e o instrumento empregado (adequação); b) a medida não seja exigível ou necessária, havendo meio alternativo menos gravoso para chegar ao mesmo resultado (necessidade/vedação ao excesso); c) os custos superem os benefícios, ou seja, o que se perde com a medida é de maior relevo que aquilo que se ganha (proporcionalidade em sentido estrito). $\mathrm{O}$ princípio pode operar também, no sentido de permitir que o juiz gradue o peso da norma em determinada incidência, de modo a não permitir que ela produza um resultado indesejado pelo sistema, fazendo assim a justiça no caso concreto.
\end{abstract}

Por conseguinte, o direito tem que ser razoável/proporcional, pois é um instrumento que requer tal fundamentabilidade. Ele deve ser observado desde a feitura de uma lei até o conteúdo de uma decisão, como também na execução do direito e deve buscar os fins almejados (BASTOS, 2002).

Desta forma, a razoabilidade deve ser visualizada durante a divisão de recursos das Instituições do Sistema de Justiça. Não sendo razoável que sobre os cidadãos necessitados se sobrecarregue o estado juiz e o estado acusação e se negue o estado defesa.

Conforme assevera Bastos (2002) O respeito à razoabilidade é muito importante, pois somente desta forma será possível se garantir uma justiça equilibrada em proporção de forças. Na vigência de um Estado Democrático de Direito o princípio da razoabilidade é um antídoto ao arbítrio e respeitador dos direitos individuais e coletivos.

Deste modo, esse princípio deve ser amplamente utilizado para que se possa superar a seletividade que existe atualmente no sistema de justiça, de forma a valorizar a defesa daqueles excluídos pela política atual implantada no Estado. 
No que tange o princípio da legalidade, este consta no inciso III, do artigo $5^{\circ}$, da Constituição de 1988, que dispões que "ninguém será obrigado a fazer ou deixar de fazer alguma coisa senão em virtude de lei’. Assim, tem o escopo de garantir a segurança jurídica, a previsibilidade dos direitos, bem como as penas previstas para aqueles que cometerem ilícitos ${ }^{7}$. Sobre o assunto, Bastos (1994, p. 24-25), comenta o seguinte:

Este princípio encontra-se com a própria noção de Estado de Direito. Estado de Direito é aquele que se submete ao próprio direito que criou, razão pela qual não deve ser motivo de surpresa constituir-se o princípio da legalidade um dos sustentáculos fundamentais do Estado de Direito.

Este princípio tem o objetivo de evitar possíveis excessos de poder do Estado, evitando que esse atue de forma arbitrária e, consequentemente, conferindo maiores garantias aos cidadãos.

Quanto ao princípio da dignidade da pessoa relacionado ao acesso à justiça, este que tem como objetivo principal, assegurar à sociedade a realização de um direito, devendo deve ser entendido como valor animador e justificador de todo ordenamento jurídico ${ }^{8}$.

Nesse sentido, é possível desenvolver uma visão conjetural desse princípio a partir da análise de alguns de seus elementos, em que a dignidade da pessoa humana pode ser vista como fator de inclusão, que reflete a o reconhecimento e proteção das diferenças entre os indivíduos, como também o respeito às diversas manifestações de consciência e de expressão do ser humano em um contexto social (CANOTILHO, 2003, p. 225-226).

Em razão da amplitude de conteúdo que o princípio da dignidade da pessoa humana carrega, é difícil estabelecer uma única definição para este ${ }^{9}$, inclusive porque ele é o fim e a razão de todo direito. Sendo assim, o mais lógico é conceitua-lo de acordo com o caso concreto e por meio de uma ponderação dialética de argumentos.

Ainda sobre esse princípio, urge comentar acerca do conflito existente entre ele e o acesso à justiça, em razão da ausência de leis mais flexíveis, isto porque no Brasil é ineficaz a

\footnotetext{
${ }^{7}$ Urge comentar que este princípio é de suma importância para o sistema penal, e está, inclusive, presente no caput do artigo $1^{\circ}$, do Código Penal, que determina que "não há crime sem lei anterior que o defina. Não há pena sem prévia cominação legal". Sendo assim, apenas a lei positivada é capaz de estipular crimes e penas.

8 Ingo Wolfgang Sarlet (2006, p.72) e José Afonso da Silva (1999, p.109), ilustres juristas, corroboram com o entendimento de que a dignidade da pessoa humana, antes de tudo, consiste na razão da existência do Estado, bem como do ordenamento jurídico.

9 "Dignidade da pessoa humana não é passível de conceituação, se bem que o juiz possa - ou melhor, deva - decidir se tal ou qual conduta ofende o referido princípio conformador do Estado Brasileiro" (SILVA NETO, 2006, p. 202). 
existência de um ordenamento tão rígido, o que acusa o desenvolvimento de leis que apenas beneficiam alguns grupos sociais.

Ante do exposto, resta claro que todos esses princípios, se devidamente aplicados, possibilitam a ampliação do o acesso à justiça, com ênfase nas pessoas menos favorecidas economicamente, cuja defesa de seus direito em sede judicial, é de difícil execução em razão da falta de informação e da precariedade dos meios disponibilizados pelo Estado.

\section{A Defensoria Pública como meio de acesso à justiça}

A garantia constitucional de acesso à justiça, tem por escopo orientar o sistema jurisdicional em sua atuação no sentido de possibilitar a acessibilidade integral e de forma equânime a todos os cidadãos. No entanto, apesar da Carta Constitucional elencar um rol de garantias Constitucionais quanto à igualdade de todos perante a lei, ainda existem diversas barreiras que dificultam ou até impossibilitam o acesso da população à justiça.

A título de exemplo, pode-se citar a carência de recursos financeiros, bem como a ausência de informação e ciência da população acerca de seus direitos, em razão de dispormos de uma lei escrita com vocabulário complexo e de difícil compreensão pela maioria dos indivíduos.

Nesse sentido, não restam dúvidas no sentido de que os problemas educacionais e socioeconômicos que acometem a população, consistem em agravantes e em verdadeiros obstáculos ao acesso à justiça, tendo em vista quantitativo elevado de analfabetos presentes na sociedade, bem como ao grande percentual de população de baixa renda. De acordo com Sadek (2001, p. 170):

\footnotetext{
$\mathrm{O}$ acesso à justiça se constitui na porta de entrada para a participação nos bens e serviços de uma sociedade. Quaisquer iniciativas que tenham por meta o combate à exclusão estarão fadadas ao fracasso se não levarem em conta garantias e direitos individuais e coletivos. Pois, não há possibilidade real de inclusão se, de fato, não houver condições efetivas de acesso à justiça. Sem o direito de recorrer à justiça, todos os demais direitos são letras mortas, garantias idealizadas e sem possibilidades de concretização.
}

Nesse diapasão, o direito de acesso à justiça tem sido entendido como uma das garantias constitucionais mais importantes dentre o rol de direitos individuais e sociais, inclusive pode 
ser visto como direito básico do sistema judicial que tenha por escopo firmar, e não só declarar, direitos universais (CAPPELLETI, 1998), sendo, dessa forma, necessário o desenvolvimento de métodos que possibilitem essa efetivação.

Ainda, conforme se infere do artigo 134 da Constituição Federal de 1988, a Defensoria Pública trata-se de instituição essencial à função jurisdicional, responsável pela a orientação jurídica e a defesa dos necessitados, em todos os graus de jurisdição:

\begin{abstract}
A Defensoria Pública é instituição permanente, essencial à função jurisdicional do Estado, incumbindo-lhe, como expressão e instrumento do regime democrático, fundamentalmente, a orientação jurídica, a promoção dos direitos humanos e a defesa, em todos os graus, judicial e extrajudicial, dos direitos individuais e coletivos, de forma integral e gratuita, aos necessitados, na forma do inciso LXXIV do art. $5^{\circ}$ desta Constituição Federal. (Redação dada pela Emenda Constitucional nº 80, de 2014).
\end{abstract}

Sendo assim, a Defensoria Pública se apresenta como instituição que busca colaborar com disseminação informacional dos direitos da população e efetivadora desses direitos, sendo uma de suas principais funções, a superação de possíveis óbices ao acesso da justiça, em especial da parte financeiramente carente da população.

Como dentre os objetivos dessa instituição, encontram-se a primazia da defesa da dignidade da pessoa humana e a redução das desigualdades sociais; sua existência é imperiosa no sentido de garantir o efetivo respeito ao princípio constitucional do contraditório e ampla defesa. Com isso, a inexistência de uma Defensoria do Estado, significa prejuízo grandioso para a população que dela depende, sendo incontroversa a importância do defensor na função jurisdicional. $^{10}$

Ademais, os dispositivos constitucionais que versam acerca da instituição de defensorias evidenciam a relevância do papel desta Instituição na assistência judicial da população. Da mesma forma, conforme comenta Juarez dos Santos (2013) pode-se entender a assistência jurídica da Defensoria na defesa de interesses coletivos e difusos, bem como a atuação na educação para os direitos, como uma prerrogativa da população.

Como a Carta Constitucional definiu a garantia do acesso à justiça como direito fundamental, conforme se infere de seu artigo $5^{\circ}$, inciso LXXIV; a Defensoria Pública consiste em mecanismo importante para fins de possibilitar a igualdade e integralidade desse acesso à

\footnotetext{
${ }^{10}$ Sobre o assunto, faz-se necessário comentar acerca do advogado dativo, sendo este um profissional nomeado para exercer a função da defensoria momentaneamente, não estando este obrigado a zelar pelos objetivos dessa instituição. Como é sabido, via de regra, o advogado atua com fulcro de priorizar seus clientes particulares, sendo sua atuação como advogado do estado algo esporádico e desinteressante, tendo em vista dificuldade em receber os honorários dessa atuação, bem como o fato do valor recebido ser, em regra, inferior ao recebido caso o cliente fosse particular.
} 
população, sendo sua atenção voltada aos necessitados, que possuem, sem dúvidas, maior dificuldade na busca e defesa de seus direitos. Suely Neder (2002, p. 04), especialista no assunto, comenta que:

“O dever do Estado de prestar assistência jurídica aos necessitados é exercitado, como munus público, em caráter de exclusividade pela Defensoria Pública”.

Sendo assim, a Defensoria Pública consiste em um dos meios de acesso à justiça, visto que presta assistência jurídica integral e gratuita aos hipossuficientes, conforme determina o art. $5^{\circ}$, LXXIV, da Constituição Federal. Logo, é notório seu papel relevante no sistema e sendo essencial a sua realização, no entanto, o que se vê é sua inserção em um sistema que a desvaloriza, sendo perceptível a priorização da acusação e o julgamento e a desmoralização da defesa.

\section{Da patente desvalorização da Defensoria Pública pelo Estado}

Apesar da indubitável importância da defensoria na promoção de direitos de todos, a parte carente da população, que compõe o grupo de necessitados e vulneráveis merecedores de atenção do Estado, não tem recebido a merecida atenção quanto à efetivação de garantias constitucionalmente protegidas (ROCHA, 2010), principalmente em razão da fragilidade da Defensoria.

Com isso, é visível a presença de um discurso quanto à garantia de assistência e amparo aos necessitados, contudo, há a inexistência de uma instituição capaz de realizar de forma qualitativa suas funções, o que a impede de possibilita a integral defesa dos direitos da população que dela depende. Sobre isso, Neder (2004), comenta:

\footnotetext{
Em verdade, agride à consciência nacional que ao Poder Público jamais faltem os recursos para implementar as ações da sua própria Advocacia-Geral e do Ministério Público, este, defensor da sociedade e fiscal da lei, mas que sejam sempre inexistentes para estruturar a Defensoria Pública. E, destaca-se ao final, tudo isso ocorre, quando, na maior parte das vezes, é contra o próprio Poder Público que o hipossuficiente deveria postular o seu direito, por ele lesado!
}

Não é de hoje que presencia esse mero e simbólico discurso jurídico no sentido da incontestável importância da Defensoria Pública no sistema jurídico, juntamente ao desamparo 
dessa instituição pelo Poder Público, o que ocasiona no agravamento e adequada assistência daqueles que dela dependem.

A Defensoria figura como elemento do sistema judicial, que tem por escopo exercer a defesa dos necessitados; juntamente com o Judiciário, que decide o conflito em questão; e o Ministério Público, que atua como fiscal da lei. Contudo, apesar da importância de todos os elementos, diversos estados da federação ainda não possuem Defensoria Pública, o que revela o enaltecimento das figuras do Magistrado e do Promotor de Justiça, em detrimento do Defensor Público.

A desigualdade no grau de importância conferido as instituições podem ser verificada de uma simples análise do quantitativo de profissionais, em que a Defensoria Pública possui 5.054 defensores, o Ministério Público detém 9.963 promotores e o Judiciário é composto de 11.835 magistrados, conforme dados divulgados pela Associação Nacional dos Defensores Públicos (ANADEP) em 2013.

Conforme mencionado, a Defensoria ocupa função essencial na Justiça, contudo muitos estados brasileiros ainda não tiveram essa instituição implantada, conforme atestam dados pela mesma pesquisa, que demonstrou que $72 \%$ das comarcas brasileiras não possuem defensores, ou seja, a Defensoria existe em apenas 754 das 2.860 comarcas existentes.

Essa desproporção no tratamento das instituições tem revelado patente desrespeito ao princípio da isonomia ${ }^{11}$, visto a inobservância deste em muitas relações, configurando uma verdadeira discriminação entre as instituições, mesmo dada a importância da defensoria para o sistema, tendo em vista que esta presta assistência aos necessitados, que constituem a maior parte da população.

\section{Considerações finais}

Conforme já comentado, a Constituição Federal de 1988 revela a busca de um Estado Social baseado na adequação de valores contrários ao individualismo no Direito e ao absolutismo no Poder. Com base nisso, a Carta Constitucional elencou garantias fundamentais

\footnotetext{
${ }^{11}$ A referida situação pode ser exemplificada na distribuição de recursos, que é realizada de forma desigual, em que se verifica que o Ministério Público e o Judiciário encontram-se em pleno funcionamento, enquanto a Defensoria é compelida a atuar de forma precária, como se pode verificar na debilidade de seus polos de atendimento. 
pautadas na igualdade, dentre as quais se destaca a assistência integral e gratuita aos hipossuficientes, nos termos do inciso LXXIV, artigo $5^{\circ}$, inciso LXXIV, da Constituição de 1988, a ser prestada pela Defensoria Pública.

Nesse diapasão, para fins de garantir a concretização dos direitos fundamentais e de todos, a Constituição assegurou a autonomia funcional, administrativa e financeira para que essa instituição pudesse desenvolver suas atividades da melhor forma possível. Logo, várias foram as garantias previstas para o seu pleno exercício e implantação, que, no entanto, tem se mostrado insuficientes.

Por meio de um comparativo entre a distribuição dos recursos pelo Estado, bem como quantitativo de Defensores, Magistrados e Promotores atuantes, percebe-se a dificuldade da Defensoria Pública em oferecer seus serviços de forma integral, principalmente em razão da ausência da instituição em diversas comarcas do país.

Isso revela uma supervalorização do estado-juiz e do o estado-acusação/fiscal da lei, em detrimento do estado-defensor, o que demonstra um prejuízo no acesso à Justiça de boa parte da população, uma vez que este último promove a defesa dos interesses jurídicos dos hipossuficientes, que consistem na maior parte da população.

Essa disparidade de investimentos, aponta uma proximidade do sistema laissezfaire, laissez-passer, le monde va de lui-même, isto porque a Justiça acaba sendo apenas de acesso único e exclusivo daqueles que consigam suportar seus custos, e aos que não conseguem, só restará a sorte.

Com isso, é evidente a ineficiência da atuação da Defensoria da atuação como representante dos grupos vulneráveis, configura uma lesão aos direitos sociais e individuais e as garantias constitucionais, o que revela a necessidade de restruturação e maior valorização da instituição, para que essa seja capaz de desenvolver de forma eficaz os preceitos e objetivos que lhe foram constitucionalmente atribuídos.

\section{Referências}

BARATtA, Alessandro. Criminologia Crítica e Crítica do Direito Penal. $3^{\text {a }}$ ed. Rio de Janeiro: Revan, 2002. 
BARROSO, Luis Roberto. Fundamentos Teóricos e Filosóficos do Novo Direito Constitucional Brasileiro (pós-modernidade, teoria crítica e pós-positivismo). In: BARROSO, Luís Roberto (Org.) A Nova Interpretação Constitucional: ponderação, direitos fundamentais e relações privadas. Rio de Janeiro: Renovar, 2003.

BASTOS, Celso Ribeiro de. Curso de Direito Administrativo, São Paulo: Editora Saraiva, 1.994.

BONAVIDES, Paulo. O Princípio da Igualdade como limitação à atuação do Estado. Revista Brasileira de Direito Constitucional. n. 2, jul./dez. - 2003. Disponível em: <http://www.esdc.com.br/seer/index.php/rbdc/article/view/47/47>. Acesso em: 19/03/2018.

FUX, Luiz. Curso de direito processual civil. Rio de Janeiro: Forense, 2004.

NEDER, Suely Pletz. Defensoria Pública - Instituição essencial ao exercício da função jurisdicional pelo Estado e à justiça. Consultoria Legislativa. 2002. Disponível em: < http://www2.camara.leg.br/a-camara/documentos-e-pesquisa/estudos-e-notas-

tecnicas/arquivos-pdf/pdf/905757.pdf > . Acesso em: 19/03/2018.

ROCHA, Paulo Osório Gomes. Concretização de direitos fundamentais na perspectiva jurídico-constitucional da Defensoria Pública: um caminho "ainda" a ser trilhado. Direito Público, v. 1, n. 17, 2010.

SANTOS, Juarez Cirino dos. Política Criminal: Realidades e Ilusões do Discurso Penal. Instituto de Criminologia e Política Criminal, 2013. Disponível em: < http://icpc.org.br/wpcontent/uploads/2013/01/realidades_ilusoes_discurso_penal.pdf >. Acesso em: 19/03/2018.

Como citar este artigo (Formato ABNT):

SANTOS, Josiéli Denise Brum dos; MARINHO, Gisanne de Oliveira; FARIAS, Athena de Albuquerque; RODRIGUES, Larice de Sousa Rodrigues. Da Igualdade de acesso à Justiça: Reflexões acerca da Defensoria Pública enquanto facilitadora de acesso dos Hipossuficientes. Id on Line Rev.Mult. Psic., 2018, vol.12, n.40, p.271-282. ISSN: 1981-1179. 